\title{
WESTERN BLOT METHOD EVALUATION FOR DETECTION OF HELICOBACTER PYLORI INFECTIONS AGAINST H. PYLORI AG IN STOOL ENZYME-LINKED IMMUNOASSAY IN ADULT EGYPTIAN PATIENTS
}

\author{
Mohamed E. Rashed $^{1 *}$, Amer M.M. ${ }^{2}$, Mostafa Elnakeeb ${ }^{3}$ and Waleed Saeed Omer ${ }^{2}$ \\ ${ }^{1}$ Microbiology Department, National organization for Research and control of biologicals (NORCB), Cairo, Egypt* \\ ${ }^{2}$ Poteny Department, Faculty of science Benha University, Benha, Egypt. \\ ${ }^{3}$ Infection Control and Epidemiology unit, Mostashfa Al Qouat Al Moussalaha, Al Maadi, Cairo, Egypt \\ Corresponding author's email: mohamed_elsayedeg@yahoo.com
}

\begin{abstract}
Helicobacter pylori infection is tremendous medical burden especially in developing countries. Various immunological tests are available for diagnosis of $H$. pylori infection. Western blot method is proven to be promising for Precise, easy reading, sensitive and specific detection of H. pylori infections, besides it also permits the detection for the different virulence factors of CagA / VacA positive strains (type I). The objective of this study is to evaluate the diagnostic value of commercial Western Blot (WB) method in the serological diagnosis of $H$. pylori infections against the H. pylori Ag in stool (HpSAg) using commercial enzyme-linked immunoassay (ELISA) in adult dyspeptic Egyptian patients. Also we investigated the prevalence of virulence factors, cytotoxin-associated gene A (CagA) and vacuolating cytotoxin A (VacA) in the infected patients. Samples from 46 adult dyspeptic Egyptian patients were tested by the two methods. WB test gave accurate confirmed result with (82.6\% accuracy and $89.5 \%$ sensitivity) compared to HpSAg test. Also the results indicated a high seroprevalence of cagA- and vacA-positive virulent $H$. pylori type I strains in adult infected population indicate that such strains may be common in this population and responsible for the majority of $H$. pylori infection among adult Egyptians. We concluded that WB method could be useful for the confirmatory detection of antibody profiles to $H$. pylori antigens and virulence factors in adult Egyptian patients.
\end{abstract}

Keywords: H. pylori; Western blot; cytotoxin-associated gene A; vacuolating cytotoxin A; Egypt

\section{Introduction}

Helicobacter pylori (H. pylori) is a recognized gramnegative, spiral-shaped gastrointestinal bacterium pathogen with world-wide distribution. According to the Centers for Disease Control and Prevention (CDC), about two-thirds of the world's population harbors the bacterium, with much higher infection rates in developing countries than in developed nations. $H$. pylori is associated with a variety of severe gastric diseases and considered as a major cause of chronic gastritis and risk factor for peptic ulcer disease and is responsible for the majority of ulcers of the stomach and upper small intestine such as gastric and duodenal ulcer, gastric adenocarcinoma and mucosa-associated lymphoid tissue lymphoma (MALT) (Parsonn et al., 1991; Parsonnet et al., 1994; Uemura et al., 2001). Classified by World Health Organization (WHO) as a class I carcinogen, $H$. pylori is considered a serious medical issue especially in developing countries. In Egypt, several studies indicated that $H$. pylori infection is highly endemic in Egypt with higher rate in rural areas and increasing trend in older ages. Also the studies suggested the relation between the H. pylori infection and progression of liver fibrosis due to Hepatitis C virus (HCV) (Ragheb et al., 2012; Rocha et al., 2005; Mohammad et al., 2008).

The virulence factors and pathogenesis, which influence the clinical outcome of $H$. pylori infection, have not fully elucidated yet. However, many studies showed that the disease causation by $H$. pylori is due to the various virulence factors where $H$. pylori strains vary in the degree of virulence (Atherton, 1997; Rudi et al., 1998; Farshad et al., 2009). H. pylori strains are divided into Type I and Type II, respectively based on the presence and absence of cagA, vacA and iceA genes which are considered to be the putative virulence factors of $H$. pylori (Censini et al., 1996; Covacci et al., 1997; Yamaoka et al., 1999). In particular cytotoxin-associated gene A ( $\operatorname{cag} \mathrm{A})$ and the vacuolating cytotoxin (vacA) are the two main $H$. pylori virulence factors found among the bacterial markers associated with pathogenesis of different strains (Farshad et al.,, 2009). This toxin CagA, produced by cagA gene, alters the structure of stomach cells and allows the bacteria to attach to them more easily. Long-term exposure to the toxin causes chronic 
inflammation(Bagnoli et al., 2005). VacA cytotoxin induces large host cell vacuoles when $H$. pylori filtrates ( Leunk et al., 1988). Both CagA and VacA cytotoxins are highly immunogenic proteinsassociated with type I strains which are responsible for severe forms of gastrointestinal diseases ( Xiang et al., 1995; Weel et al., 1996; Enroth et al., 2000; Farshad et al.,, 2009).

The standard primary diagnostic procedures for $H$. pylori infection, including endoscopy and histology, or bacterial culture of biopsied specimen are endoscopic invasive and not available in most clinics in the developing countries. While the non-invasive breath test are useful in the diagnosis of $H$. pylori but expensive due to the need for expensive mass spectrometers and the availability of ${ }^{13} \mathrm{C}$ urea limits the use of the breath test in the developing countries. On the other hand, the indirect immunological tests are commercially available, accurate and cheap and measure the immune system response to an infectious agent and the components of the agent itself.

We therefore aimed first to evaluation of western blot (WB) method for serologic diagnosis of $H$. pylori infections against the common enzyme-linked immunosorbent assay (ELISA) by detection of antibodies to $H$. pylori virulence factors such as CagA and VacA using commercial immunoblotting test compared to H. pylori Ag in stool as a gold standard. We also investigated the frequency of occurrence of serological markers of $H$. pylori virulence factor(s) of type I $H$. pylori strains in adult Egyptian patients.

\section{Patients and Methods}

This study was conducted including 46 of dyspeptic individuals ( 32 males and 14 females) suspected to be infected with $H$. pylori infection. The range of the patients' age varied from 20 to 70 years old with a median age of 40 years old ( 40.5 males and 40 females) see Table 1.

Blood specimens for serological testing was drawn, where $5 \mathrm{ml}$ venous blood was taken and collected in dry tube, after clotting, the sera were separated by centrifugation for ( 10 minutes at 3000 $\mathrm{rpm}$ ) divided into aliquots that may be refrigerated at $2-8{ }^{\circ} \mathrm{C}$ for up to seven days or frozen for up to six months till used. Samples of stools were collected in dry clean tubes and stored at $\left(-20^{\circ} \mathrm{C}\right)$ until used. ELISA measurement of $H$. pylori Antigen $(\mathrm{HpSAg})$ in human stools was performed and the results were interpreted using $H$. Pylori Antigen E32-320 manufacturer's instructions (Immunospec, USA). While serum samples were examined for $H$. pylori antibodies to six virulent $H$. pylori antigens by Wester blot test using the commercial Helicobacter pylori LINE IgG / IgA Line (H. pylori line) immunoblot kit WE243G96 (Sekisui Virotech, Japan). Qualitative detection of H. pylori antibodies in human serum to the following six virulent antigens: cagA (cytotoxin-associated geneA), vacA (vacuolating cytotoxin A), UreA (urease A), p30 (OMP), p25 (OMP) and p19 (OMP), according to the manufacturer's instructions. Additional H. pylori IgA antibody test ((HpIgA) was performed for 20 randomly selected samples using $H$. pylori IgA E30-274. Assay values were calculated according to the manufacturer's instruction (Immunospec, USA) as shown in Table 2.

\section{Statistical Analysis}

Statistical analyses were performed using SPSS software (version 16). Sensitivity, specificity, predictive values of positive and negative results were calculated in accordance with standard methods suggested by Fleiss (Fleiss et al., 2003). Chi-square test for significance used to compare proportions between qualitative parameters. The result considered significant if the probability (P-value) was < 0.05 .

Table 1: The distribution of the participated cases

\begin{tabular}{ccccccc}
\hline Ages & \multicolumn{2}{c}{ Males } & \multicolumn{2}{c}{ Females } & \multicolumn{2}{c}{ Total } \\
\cline { 2 - 7 }$<=30$ & Number & Percent & Number & Percent & Number & Percent \\
\cline { 2 - 7 } $31-40$ & 5 & $15.6 \%$ & 2 & $14.3 \%$ & 7 & $15.2 \%$ \\
$41-50$ & 11 & $34.4 \%$ & 6 & $42.9 \%$ & 17 & $37 \%$ \\
$51-60$ & 3 & $34.4 \%$ & 2 & $14.3 \%$ & 13 & $28.3 \%$ \\
$61+$ & 2 & $6.4 \%$ & 2 & $14.3 \%$ & 3 & $10.9 \%$ \\
Total & 32 & $69.6 \%$ & 9 & $30.4 \%$ & 46 & $100 \%$ \\
\hline
\end{tabular}

Table 2: The parameters used for interpretation of the results according to the manufacturer's instructions

\begin{tabular}{cccc}
\hline & $\begin{array}{c}\text { H. Pylori Antigen } \\
(\mathrm{HpSAg})\end{array}$ & H. pylori line & $\begin{array}{c}\text { H. pylori IgA } \\
\text { (HpIgA) }\end{array}$ \\
\hline Negative & $<15 \mathrm{ng} / \mathrm{ml}$ & No band or only one band of p30, p19 & $<0.9^{*}$ \\
CagA & $>1.1^{*}$ \\
Positive & $>20 \mathrm{ng} / \mathrm{ml}$ & $\begin{array}{c}\text { or } \\
\text { Arise from } \geq 2 \text { bands of the following: } \\
\text { VacA, p30, UreaA, p25, p19 }\end{array}$ \\
Borderline & $15-20 \mathrm{ng} / \mathrm{ml}$ & $\begin{array}{c}\text { Only one band of VacA, UreaA, p25 } \\
\text { *ratio between the average absorbance value of sample and that of the cut- off. }\end{array}$ & $0.9-1.1^{*}$ \\
\hline
\end{tabular}




\section{Results}

All specimens were tested for with ( $\mathrm{HpSAg})$ and $H$. pylori line for $H$. pylori infection was diagnosed by $\mathrm{HpSAg}$ as a gold standard in 38 patients $(82.61 \%)$, also $H$. pylori line gave the same detection percentage as shown in Fig. 1. However, the results were not matched as both tests detected the infection in $73.9 \%$ (positive result) and clear $8.7 \%$ from being infected (negative results) as shown in Table 3 . The sensitivity and positive predictive value were $89.47 \%$, while the specificity and negative predictive value were $50 \%$ as exhibited in Table 4 . The H. pylori line exhibited significant association with the standard method HpSAg HpSAg ( $<0.01$ ) which showed that the H. pylori line could be a reliable method to detect the $H$. pylori infection. Also there was no significance difference in results of $H$. pylori line test neither between different genders nor among different ages, see Fig. 2. For the HpIgA results of the 20 randomly samples, there was no statistically agreement between their result neither with the H. pylori line nor with HpSAg (p > 0.05). Only 2 (10\%) cases shared positive HpIgA results with the other tests, $\mathrm{HpIgA}$ results was aligned with $\mathrm{HpSAg}$ test in $35 \%$ of samples ( $15 \%$ negative and $20 \%$ positive), while the percentage decreased with $H$. pylori line test to $20 \%$ ( $5 \%$ negative and $15 \%$ positive) as presented in Fig. 3.

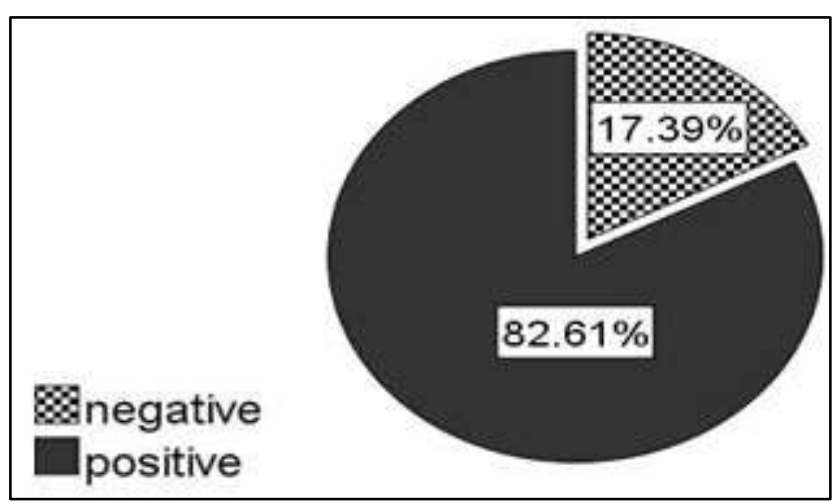

Fig. 1: laboratory results of $\mathrm{HpSAg}$ and $H$. pylori line tests for $H$. pylori infection. Both tests gave the same total percentage results regarding all the specimens that was tested

Table 3: Comparison between HpSAg and H. pylori line in diagnosing H. pylori infections

\begin{tabular}{|c|c|c|c|c|c|}
\hline & & & \multicolumn{2}{|c|}{ H. Pylori Line } & \multirow{2}{*}{ Total } \\
\hline & & & negative & positive & \\
\hline \multirow{2}{*}{ H. pylori $\mathrm{Ag}$ in stool } & negative & $\begin{array}{l}\text { Count } \\
\% \text { of Total }\end{array}$ & $\begin{array}{l}4 \\
8.7 \%\end{array}$ & $\begin{array}{l}4 \\
8.7 \%\end{array}$ & $\begin{array}{l}8 \\
17.4 \%\end{array}$ \\
\hline & positive & $\begin{array}{l}\text { Count } \\
\% \text { of Total }\end{array}$ & $\begin{array}{l}4 \\
8.7 \%\end{array}$ & $\begin{array}{l}34 \\
73.9 \%\end{array}$ & $\begin{array}{l}38 \\
82.6 \%\end{array}$ \\
\hline Total & & $\begin{array}{l}\text { Count } \\
\% \text { of Total }\end{array}$ & $\begin{array}{l}8 \\
17.4 \%\end{array}$ & $\begin{array}{l}38 \\
82.6 \%\end{array}$ & $\begin{array}{l}46 \\
100.0 \%\end{array}$ \\
\hline
\end{tabular}
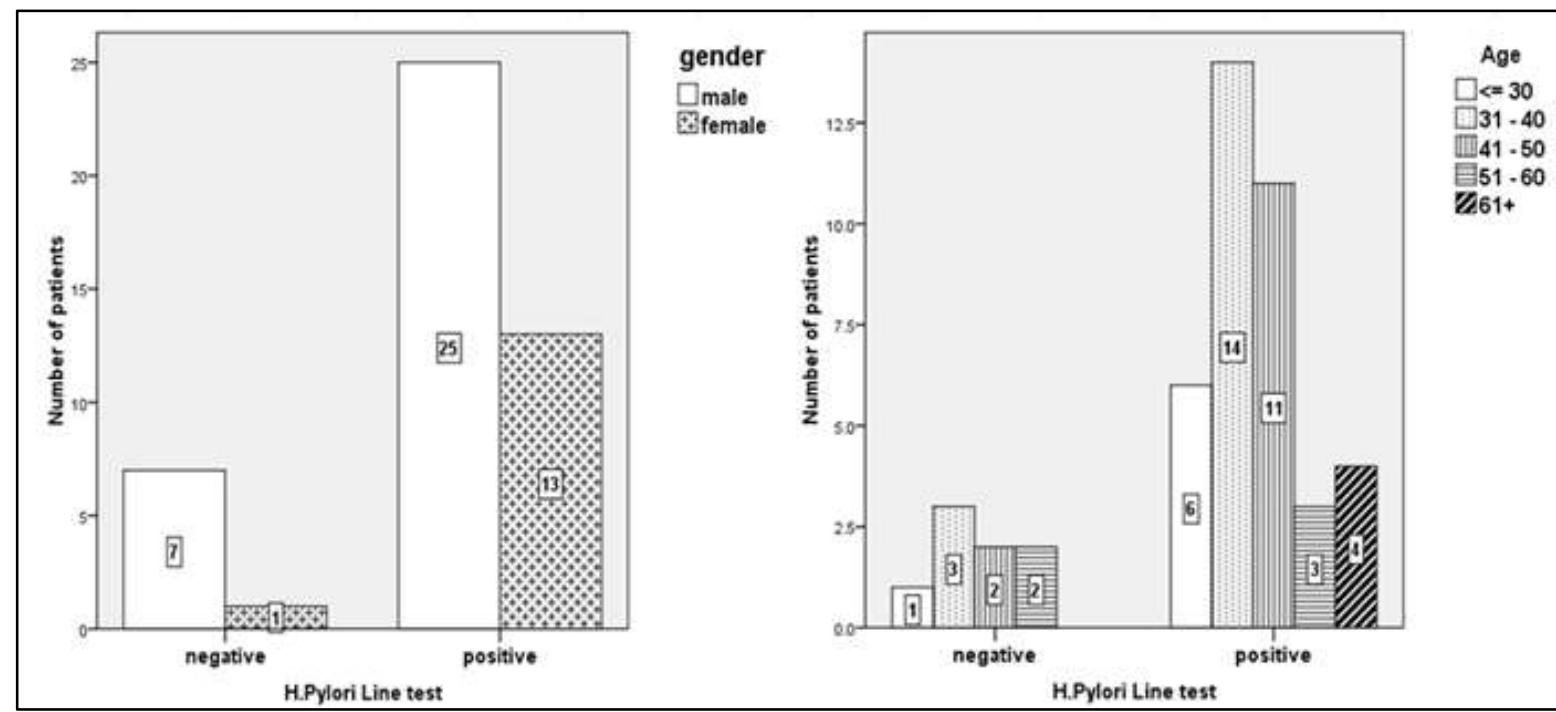

Fig. 2: The distribution of the results of $H$. pylori line test regarding the gender and the ages among 46 dyspeptic patients tested for $H$. pylori infection. 

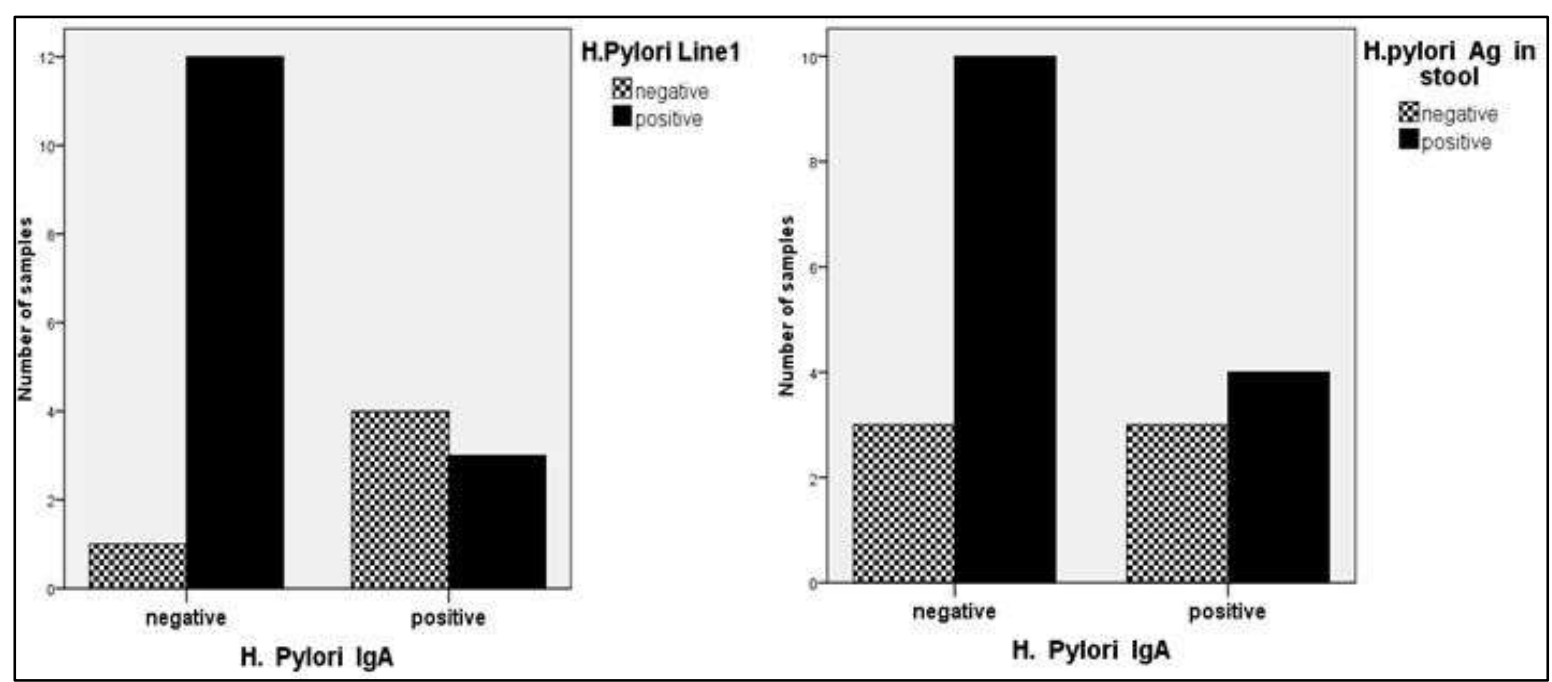

Fig. 3: the agreement of the results of HpIgA test with HpSAg and $H$. pylori line in diagnosing $H$. pylori infections

Table 4: Diagnostic evaluation of $H$. pylori line test against HpSAg test (as a gold standard) in the detection of H. pylori infection.

\begin{tabular}{ll}
\hline Sensitivity & $89.47 \%$ \\
Specificity & $50 \%$ \\
positive predictive value & $89.47 \%$ \\
Negative predictive value & $50 \%$ \\
Accuracy & $82.61 \%$ \\
Prevalence & $82.61 \%$ \\
\hline
\end{tabular}

Higher number of antibodies to all six virulent antigens of $H$. pylori was present in positive cases tested by the $H$. pylori line and HpSAg test as shown in Fig. 2. Antibodies to $\mathrm{CagAa}$ VacA and UreaA were predominated with 54.3\%, $30.4 \%$ and $37 \%$, respectively which indicated the high prevalence of virulent strain type I. Although the CagA antigen was confirmed in positive $\mathrm{HpSAg}$ test with the highest rate up to $55.3 \%$ but there was no significant association between the presence of CagA and positive result gave by $\mathrm{HpSAg}$ test. On the other hand, there was a strong relation between the positive results of $H$. pylori line test and presence of CagA antigen. About $65.8 \%$ of positive results of $H$. pylori line test were due to the presence of CagA antigen. The prevalence of VacA antigen did not change in the positive results of both tests, as $36.8 \%$ of the positive results showed presence of VacA antigen. CagA antigen was detected with VacA in $10.9 \%$ of the samples tested, with other antigen than VacA in $26.09 \%$ of the cases. While VacA band associated with other bands (p30, UreaA, $\mathrm{p} 25, \mathrm{p} 19)$ in $13.04 \%$ of the cases. While only $6.52 \%$ of the positive results by $H$. pylori line test was due to the presence 2 bands other than CagA and VacA as in Table 5.

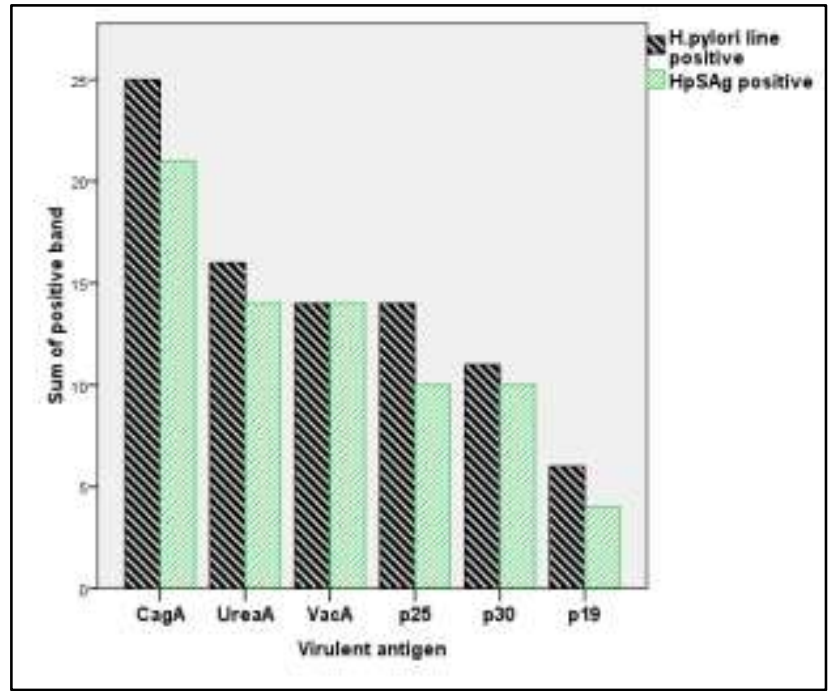

Fig. 4: The antibodies to six virulent antigens of $H$. pylori in positive patients by $H$. pylori line and HpSAg test

Table 5: Distribution of the associated positive bands in the samples of 46 dyspeptic patients using $H$. pylori line test

\begin{tabular}{|l|l|l|}
\hline Positive bands & $\begin{array}{l}\text { Number of } \\
\text { cases }\end{array}$ & $\begin{array}{l}\text { Percent } \\
\%\end{array}$ \\
\hline CagA + VacA & 5 & $10.9 \%$ \\
\hline $\begin{array}{l}\text { CagA + other antigen other } \\
\text { than VacA }\end{array}$ & 12 & $26.09 \%$ \\
\hline $\begin{array}{l}\text { VacA + other antigen other } \\
\text { than CagA }\end{array}$ & 6 & $13.04 \%$ \\
\hline $\begin{array}{l}\text { Two bands of p30, UreaA, } \\
\text { p25, p19 }\end{array}$ & 3 & 6.52 \\
\hline
\end{tabular}

\section{Discussion}

According to the Centers for Disease Control and Prevention (CDC), people should be tested for $H$. pylori when they have active gastric or duodenal ulcers or a documented history of ulcers. While in developing countries where poor hygiene and sanitation conditions could easily facilitate the transmission of the infection. $H$. 
pylori infection is a potential threat especially when associated with other endemic chronic disease as in elder people (Ragheb et al., 2012; Rocha et al., 2005). Early treatment can counteract the development of the serious complications such as gastric carcinoma. Therefore diagnosis of $H$. pylori infection as soon as possible should be attempted. Detection methods of $H$. pylori infection can be classified into invasive and non-invasive methods. The invasive methods where the pathogen is found in biopsies include the rapid urease test, histology, culture and PCR. The non-invasive tests include the urea breath test, the stool antigen test and detection of antibodies in the serum. While invasive methods is the accurate standard diagnostic methods, their expenses hinder their application in the developed countries. On the other side, non-invasive tests are not absolutely accurate on their own but are simple, commercially available and easy to be performed by provincial health laboratories especially immunological tests. Immunochemical tests for $H$. pylori vary in different populations, largely due to their socioeconomic status; the $H$. pylori strain heterogeneity and variations in antigenic preparations. Therefore, the usages of these tests need to be confirmed in the target populations. Both ELISA and Western blot is commonly wide spreading methods for immunological tests. There are several ELISA commercial kits for detection of either antigen or antibodies against $H$. pylori. Also the presence of antibodies against $H$. pylori antigens can be evaluated by immunoblotting as Western blot (WB) ( Figueiredo et al., 2001; Oleastro et al., 2002). Regarding being expensive and time-consuming, Western Blot is less likely to give false positive results as it can effectively distinguish $H$. pylori antibodies and other antibodies. Finally immunoblotting allows the detection of antibodies to $H$. pylori virulence factors such as CagA and VacA (Figueiredo et al., 2001). This study aimed to evaluate immunoblotting technique for detection of $H$. pylori infection using commercial Western blot kit $(H$. pylori line) compared to H. pylori Ag in stool (HpSAg) by ELISA method as gold standard. HpSAg was proven to be of high specificity and sensitivity test for diagnosis of $H$. pylori infection or whether treatment for an $H$. pylori infection has been successful (Ohkura et al., 2000; She et al., 2009; Rashed, 2015). A total of 46 adult Egyptian dyspeptic patients (age range 20-70 years old) were tested for $H$. pylori infection by both $\mathrm{HpSAg}$ and $H$. pylori line methods. The $H$. pylori line gave the same general percentage results as $\mathrm{HpSAg}$ with remarkable sensitivity $(\approx$ $90 \%)$ and accuracy $(\approx 83 \%)$ with no significant difference between the results of the two tests. The specificity and negative predictive value was remarkably low $(50 \%)$ due to the small proportion of uninfected patients evaluated in these current study. Compared with $\mathrm{HpSAg}, H$. pylori line correctly identified about $74 \%$ of the positive results detected by HpSAg. About 9\% was positively detected by H. pylori line while showed negative results by $\mathrm{HpSAg}$, which may related to the nature of method itself as the Western blot test seems to be more sensitive than ELISA especially with low levels of antibodies as individual bacterial proteins are better exposed (Nilsson et al., 1997). On the other side, the positive results of $\mathrm{HpSAg}$ which were undetected by $H$. pylori line, could be explained that the $H$. pylori infection was due to strains other than type I, as Pylori line test specifically detect only the virulent factors of $H$. pylori type I strains. The same explanations could be adapted for the unassociated results of HpIgA test for 20 randomly samples with $H$. pylori line results, as there was only $20 \%$ agreements between the results of the two tests. However HpIgA is known to be less sensitive to rely on for detection of $H$. pylori infection as observed in other study done also on adult Egyptian patients (Rashed, 2015). Collectively, these results showed that most of the $H$. pylori infection was caused by type I strains of $H$. pylori.

Based on these observations, we also investigated the prevalence of serological markers of $H$. pylori virulence factor(s) especially CagA and VacA of type I $H$. pylori strains among infected adult Egyptian patients. H. pylori line used for qualitative detection of Helicobacter pylori specific IgG and IgA-antibodies for 6 high specific antigens expressed by type I strain. Phenotype $1 \mathrm{H}$. pylori strain is believed to be more pathogenic than phenotype 2 . It was observed that virulent type I has a correlation with higher risk of carcinoma development (Roesler et al., 2014). Phenotype $1 \mathrm{H}$. pylori strain is characterized by the presence of both cagA and vacA genes which are responsible for secretion of CagA and VacA toxins, respectively. CagA protein is a highly immunogenic protein which is responsible for severe forms of gastrointestinal complications such as gastric adenocarcinoma and duodenal ulcer ( Blaser et al., 1995; Nomura et al., 2002). There was more than $50 \%$ of CagA-positive H. pylori in the patients infected by $H$. pylori which reflect the high prevalence of CagA-positive $H$. pylori infections. These results were different than a study done on rural and semirural Egyptian citizens, as the study reported that CagA positive strains are not common in the tested subjects, however, the study observed also that seropositive for antiCagA is significantly increased with increasing ages (EL Dine et al., 2008) which could explaine the strong significant association between the higher frequency of seropositive CagA and ages over 30 years. While there was no relation between the CagA positive results of the different genders. VacA is the second most important toxin in the array of $H$. pylori's virulence factors. Gastric epithelial cell injury is caused by a vacuolating cytotoxin (VacA), which induces host cell vacuolation and, finally, cell death. Our results showed also a high seropositive VacA (40\%) in the infected patients. slightly less than $50 \%$ of the positive results had either CagA or VacA combined with different virulent factor. 


\section{Conclusion}

One immunological test (detecting specific antibody or bacterial antigen) could not be reliable to give accurate determination of $H$. pylori infection. Our finding indicated the western blot is a reliable method which could be used as a confirmatory accurate test to diagnose $H$. pylori infection especially to determine seropositivity anti-CagA, VacA virulence factor status of adult Egyptian dyspeptic patients. Also our study showed high prevalence of phenotype 1 strains in positive detected $H$. pylori infected adult Egyptian patients. However, other studies are still needed to confirm the genotypes of $H$. pylori strains including larger patient populations and control groups, in our country.

\section{References}

Atherton JC (1997) The clinical Relevance of Strain Types of Helicobacter pylori. Gut 6: 701-703. DOI: 10.1136/gut.40.6.701

Bagnoli F, Buti L, Tompkins L, Covacci A and Amieva MR (2005) Helicobacter pylori CagA Induces a Transition from Polarized to Invasive Phenotypes in MDCK Cells. Proc. Natl. Acad. Sci. USA. 45: 16339-16344. DOI: 10.1073/pnas.0502598102

Blaser MJ, Perez-Perez GI, Kleanthous H, Cover TL, Peek RM, Chyou PH, Stemmermann GN and Nomura A.(1995) Infection with Helicobacter pylori strains possessing cagA is associated with an increased risk of developing adenocarcinoma of the stomach. Cancer Res. 10: 21112115.

Censini, S, Lange C, Xiang Z, Crabtree JE, Ghiara P, Borodovsky M, Rappuoli R and Covacci A (1996) CagA pathogenicity island of Helicobacter pylori, encodes type 1-specific and disease-associated virulence factors. Proc. Natl. Acad. Sci. USA. 25: 14648-14653. DOI: 10.1073/pnas.93.25.14648

Covacci A, Falkow S, Berg DE and Rappuoli R (1997) Did the inheritance of a pathogenicity island modify the virulence of Helicobacter pylori? Trends Microbiol. 5: 205-208. DOI: 10.1016/S0966-842X(97)01035-4

El Dine SS, Mubarak M and Salama R, El Raziky M and El Sherbiny E (2008) Low seroprevalence of anti-CagA antibodies in spite of high seroprevalence of anti-H. Pylori antibodies in rural egyptian community. Res. J. Med. Med. Sci. 2: 118-123.

Enroth H, Kraaz W, Engstrand L, Nyrén O and Rohan T (2000) Helicobacter pylori strain types and risk of gastric cancer: A case-control study. Cancer Epidemiol. Biomarkers \& Prevention 9: 981-985.

Farshad S, Japoni A and Kalani M (2009) Genes associated UreAB, VacA, CagA strains of H. pylori with ulcer medication without ulcers. Hormozgan Med. J. 13: 81-87.

Figueiredo C, Quint W, Nouhan N, Munckhof Hvd, Herbrink P, Scherpenisse J, Boer Wd, Schneeberger P, Perez-Perez G, Blaser MJ, and Doorn L-Jv (2001). Assessment of Helicobacter pylori vacA and cagA genotypes and host serological response. J. Clin. Microbiol. 4: 1339-1344. DOI: 10.1128/JCM.39.4.1339-1344.2001
Fleiss JL, Levin B and Paik MC (2003) Statistical methods for rates and proportions, 3rd edition. John Wiley \& Sons. DOI: $10.1002 / 0471445428$

Leunk RD, Johnson PT, David BC, Kraft WG and Morgan DR (1988) Cytotoxic activity in broth-culture filtrates of Campylobacter pylori. J. Med. Microbiol. 2: 93-99. DOI: 10.1099/00222615-26-2-93

Rashed ME, Yassin MH, AbdelAllah NH and Zidan T (2015) Immunological tests comparison for the detection of Helicobacter pylori infection in Egyptian adult patients. IJMRPS 12: 42-48.

Mohammad MA, Hussein L, Coward A and Jackson SJ (2008) Prevalence of Helicobacter pylori infection among Egyptian children: Impact of social background and effect on growth. Pub. Health Nutrition 3: 230-236. DOI: $10.1017 / \mathrm{s} 1368980007000481$

Nilsson I, Ljungh A, Aleljung P and Wadström T (1997) Immunoblot assay for serodiagnosis of Helicobacter pylori infections. J. Clin. Microbiol. 2: 427-432.

Nomura AM, Perez-Perez GI, Lee J, Stemmermann G and Blaser MJ (2002) Relation between Helicobacter pylori cagA status and risk of peptic ulcer disease. Am. J. Epidemiol. 11: 1054-1059. DOI: 10.1093/aje/155.11.1054

Ohkura R, Miwa H and Nagahara A Ohta K, Sato K, Yamada T and Sato N (2000) usefulness of a novel enzyme immunoassay for the detection of Helicobacter pylori in feces. Scand. J. Gastroenterol. 1: 49-53.

Oleastro M, Matos R, Cabarl J, Barros R, Lopes AI, Ramalho P and Monteiro L (2002) Evaluation of a western blot test, Helico Blot 2.1, in the diagnosis of Helicobacter pylori infection in a pediatric population. Helicobacter 3: 210215. DOI: $10.1046 / \mathrm{j} .1523-5378.2002 .00083 . x$

Parsonnet J, Friedman GD, Vandersteen DP, Chang Y, Vogelman JH, Orentreich N and Sibley RK (1991) Helicobacter pylori infection and the risk of gastric carcinoma. N. Engl. J. Med.16: 1127-1131. DOI: 10.1056/NEJM199110173251603

Parsonnet J, Hansen S, Rodriguez L, Gelb AB, Warnke RA, Jellum E, Orentreich N, Vogelman JH and Friedman GD (1994) Helicobacter pylori infection and gastric lymphoma. $N$. Engl. J. Med. 18: 1267-1271. DOI: 10.1056/NEJM199405053301803

Ragheb MM, Awad MME, Tag Eldeen LE and Dosoki TM (2012) Impact of Helicobacter pylori infection on liver fibrosis in egyptian patients with chronic hepatitisC. J. Advan. Res. 3: 287-293. DOI: 10.1016/j.jare.2011.09.004

Rocha M, Avenaud P, Ménard A, Bail B Le, Balabaud C, BioulacSage P, Queiroz DM de M and Mégraud F (2005) Association of Helicobacter species with hepatitisC cirrhosis with or without hepatocellular carcinoma. Gut 3: 396-401. DOI: 10.1136/gut.2004.042168

Roesler BM, Rabelo-Gonçalves EMA and Zeitune JMR (2014) Virulence factors of Helicobacter pylori: A review. Clin. Med. Insights Gastroenterol. 7: 9-17. DOI: 10.4137/CGast.S13760 
Rudi J, Kolb C, Maiwald M, Kuck D, Sieg A, Galle PR and Stremmel W (1998) Diversity of Helicobacter pylori vacA and cagA genes and relationship to VacA and CagA protein expression, cytotoxin production, and associated diseases. J. Clin. Microbiol. 4: 944-948.

SheRC, Wilson AR and Litwin CM (2009) Evaluation of Helicobacter pylori immunoglobulin $\mathrm{G}(\mathrm{IgG}), \operatorname{IgA}$, and IgM serologic testing compared to stool antigen testing. Clin.Vaccine Immunol. 8: 1253-1255. DOI: 10.1128/CVI.00149-09

Uemura N, Okamoto S, Yamamoto S, Matsumura N, Yamaguchi S, Yamakido M, Taniyama K, Sasaki N and Schlemper RJ (2001) Helicobacter pylori infection and the development of gastric cancer. N. Engl. J. Med. 11: 784-789. DOI: 10.1056/NEJMoa001999
Weel JFL., van der Hulst RWM, Gerrits Y, Roorda P, Feller M, Dankert J, Tytgat G N J and van der Ende A (1996) The interrelationship between cytotoxin-associated gene A, vacuolating cytotoxin, and Helicobacter pylori-related diseases. J. Infect. Dis. 5: 1171-1175. DOI: 10.1093/infdis/173.5.1171

Xiang Z, Censini S, Bayeli PF, Telford JL, Figura N, Rappuoli R and Covacci A (1995) Analysis of expression of CagA and VacA virulence factors in 43 strains of Helicobacter pylori reveals that clinical isolates can be divided into two major types and that CagA is not necessary for expression of the vacuolating cytotoxin. Infect. Immun. 1: 94-98.

Yamaoka Y, Kodama T, Gutierrez O, Kim JG, Kashima K and Graham DY (1999) Relationship between Helicobacter pylori iceA, cagA, and vacA status and clinical outcome: Studies in four different countries. J. clin. microbiol. 7: 2274-2279. 